\title{
A Study on the Application of Automated Essay Scoring in College English Writing Based on Pigai
}

\author{
Wenxin Zhu \\ Jiangsu University Jingjiang College \\ Zhenjiang, Jiangsu, China \\ 19473856@qq.com
}

\begin{abstract}
In recent years, Automated Essay Scoring (AES) has been more and more widely used in college English writing. This article takes Pigai as an example to introduce the advantages and disadvantages of AES, and though questionnaire survey and interviews, analyzes the influence of AES on college English writing. It proposes how to further apply AES in the practice and reform of college English writing.
\end{abstract}

Keywords-Computer Assisted Foreign Language Writing; Automated Essay Scoring; college English writing; Pigai

\section{INTRODUCTION}

Writing has always been an essential part in English teaching. With the application of modern information technology in education, Computer Assisted Foreign Language Writing, or CAFLW, has drawn increasingly more attentions from teachers, researchers, universities and some commercial companies. Chen (2011) holds that CAFLW helps to cultivate students self-learning habits, enhance learners' motivation and improve their abilities to write in foreign languages. [1]

Based on the automatic scoring and modification functions offered by Pigai (www.pigai.org), this paper aims to look into the effect of automated essay-scoring software on college students' writing, analyze the advantages and disaantages of automated essay scoring and explore the further application of automated essay scoring in college English writing.

\section{AUTOMATED ESSAY SCORING}

Automated Essay Scoring (AES) is defined as the computer technology that evaluates and scores the written prose. (Shermis \& Burstein, 2003) [2]It is designed to help teachers and testing companies to make essay assessment. Some of the most widely used AES systems: Project Essay Grader $^{\mathrm{TM}}$ (PEG), Intelligent Essay Assessor ${ }^{\mathrm{TM}}$ (IEA), E-rater ${ }^{\circledR}$ and Criterion ${ }^{\text {MM }}$, IntelliMetric ${ }^{\text {TM }}$ and MY Access! ${ }^{\circledR}$, and Bayesian Essay Test Scoring System ${ }^{\mathrm{TM}}$ (BETSY). (Dikli, 2006)[3]

Starting from 2012, Pigai, a web-based AES system has been put into use in China. Up to now, Pigai has viewed more than 500 million essays. As writing analyzing tool, Pigai includes a group of programs that identify errors in grammar, usage, diction and make an overall evaluation in organization and content relevance. The technologies that Pigai uses mainly include Natural Language Processing (NLP), deep learning and cloud computing. As the core technology, NLP technology comprises a variety of fields including corpus-based methods, discourse methods, formal models, machine translation, natural language generation, and spoken-language understanding (Salem, 2000). [4] Being a typical application of NLP technology, Pigai makes a comprehensive application of corresponding processing techniques and research results including part-of-speech tagging, syntactic analysis, natural language generation, text classification, information retrieval, information extraction, etc.

By comparing and analyzing the essay submitted and its standard corpora, the Pigai system measures the distance data between the two. Then through 192 different kinds of language analyses, the distance is converted into user-understandable scores, general comments and comments by sentence. See Fig. 1 below:

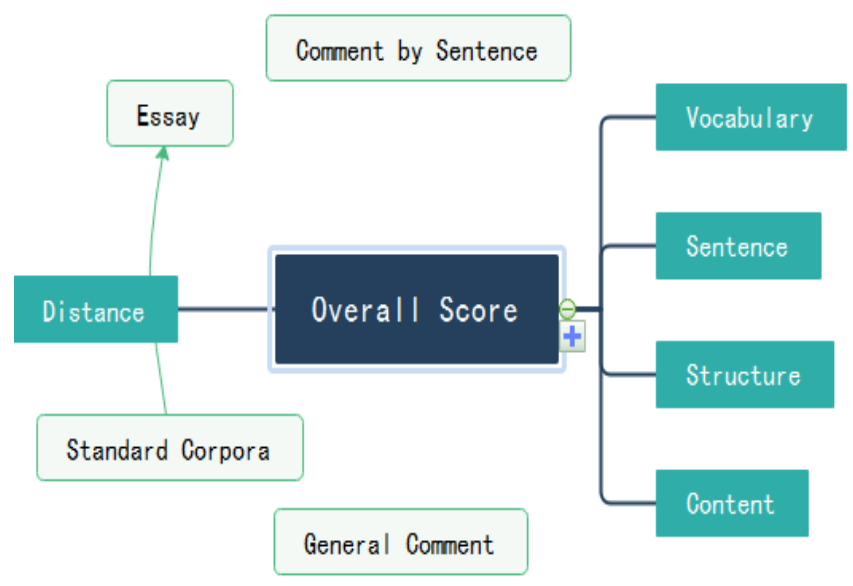

Fig. 1. The Architecture of Pigai

\section{The AdVANTAges of AES IN ENGLiSH WRITING PRACTICE}

\section{A. Time Saving}

At present, the college English teaching in most colleges has the problem that the class sizes is growing and teachers are teaching too many classes, which directly leads to less assigned compositions. Take Jiangsu University Jingjiang College for example: the standard size for each class is 30 , and one teacher is assigned with 6 classes which add up to around 180 students and 12 to 18 classes per week. It is impossible 
for most teachers to give students meaningful and detailed feedback and correction on writing assignments. Most teachers do not assign more than three writings per semester. Also, students may have to wait for days or weeks to get a grade and feedback, and the waiting greatly affects students' enthusiasm to write and improve their essays. In this sense, with the instant scoring and feedback it provides, AES can be a useful tool to help both the teachers and students in English writing.

\section{B. Instant Feedback}

Instead of handling in a notebook and getting a grade from the teachers a few days later, students now can click the "send" button and receive a grade back instantly, along with comments and correction. After that, instead of being done with the essay, the students can rewrite and make adjustment to the essay and try to improve their grade. A one-time assignment is thus turned into a process of improvement.

The table below is the performance of students for one semester:

TABLE I.

STUDENTS PERFORMANCE FOR ONE SEMESTER

\begin{tabular}{|c|c|c|c|c|}
\hline $\begin{array}{c}\text { Essay } \\
\text { No. }\end{array}$ & Topic & $\begin{array}{c}\text { Students } \\
\text { Numbers }\end{array}$ & $\begin{array}{c}\text { Average } \\
\text { Submission }\end{array}$ & $\begin{array}{c}\text { Average } \\
\text { Grade }\end{array}$ \\
\hline 406035 & $\begin{array}{c}\text { A classmate of yours } \\
\text { who has influenced } \\
\text { you most in college }\end{array}$ & 148 & 10.86 & 69.55 \\
\hline 458244 & $\begin{array}{c}\text { A Most Unlucky } \\
\text { Day }\end{array}$ & 146 & 9.80 & 65.96 \\
\hline 461566 & Plastic Surgery & 146 & 6.11 & 75.07 \\
\hline 468578 & Credit Card & 145 & 6.40 & 77.40 \\
\hline 468582 & $\begin{array}{c}\text { More People } \\
\text { Choosing Overseas } \\
\text { Destinations for } \\
\text { Their Holidays }\end{array}$ & 146 & 5.90 & 79.57 \\
\hline
\end{tabular}

As can be seen from the data, the average number of submissions by students when they first started using Pigai was 10.8 times. Of the actual data, 28 students submitted only once and have not made any modification. 57 students submitted more than 10 times, and 24 students submitted more than 20 times, which is quite impossible with human graders. Fig. 2 below shows the score track of a student modifying his essay on the website of Pigai.

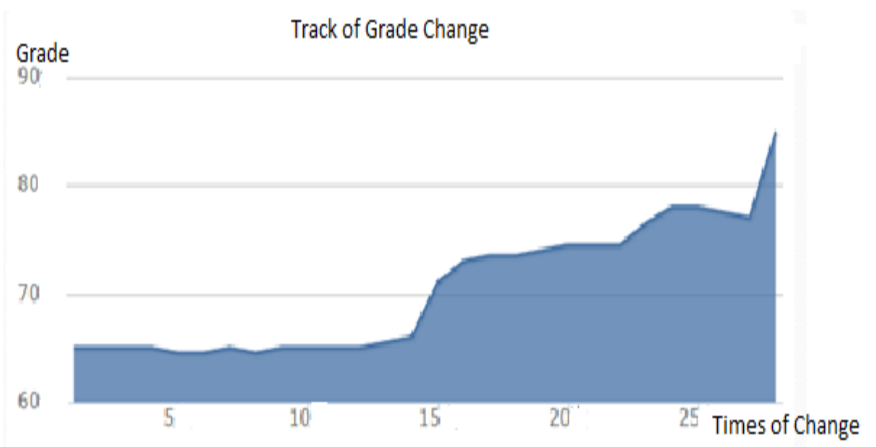

Fig. 2. Sample track of scoring from Pigai

This student has submitted his essay 28 times. And with each correction and modification he made, his score changed. This kind of instant feedback and scoring is very much like how a game works psychologically. Many students these days get addicted to video games because they can get simultaneous feedback and recognition. With instant feedback, students are more willing to work on their essays for improvement. In a questionnaire survey of, $71.5 \%$ students say the AES boost their enthusiasm for improving their essays.

\section{Intelligent Feedback}

Pigai system intelligently evaluates students' essays from four dimensions: vocabulary, sentence, structure and content. When scoring, it provides a bar graph to show the scores of each item and an overall comment, as shown below, giving students a general impression.

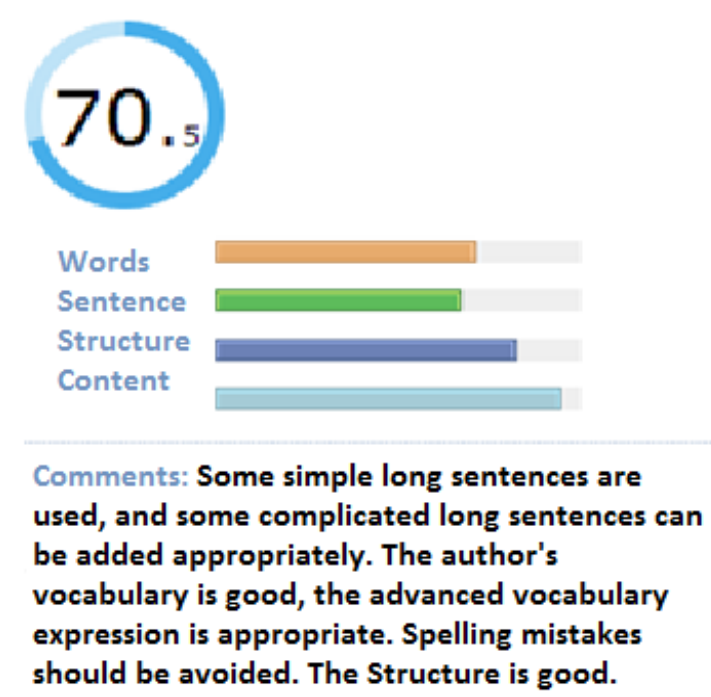

Fig. 3. Sample Overall Comment of Pigai

As for teachers, Pigai offers customized options to adjust the percentage of each dimension. It also provides different scoring formulas from elementary school, to junior high school, high school, SAT, CET-4, CET-6, TEM-4, TEM-8, IELTS, TOEFL, etc., so that reasonable feedback is given according to the specific requirements and the level of students.

Comment by sentence is the feature rated highest by the students in the survey. It analyzes an essay sentence by sentence and tells the students what mistakes they have made, and for misspelling, wrong words and grammatical errors, it gives suggestions for correction or improvement. What's more, it shows the user a corpus frequency chart (Fig. 4), so that English learners can search, view, compare or summarize the differences between different corpora and their compositions, and modify them according to the corpus statistics (Hou, 2015)[5]. 


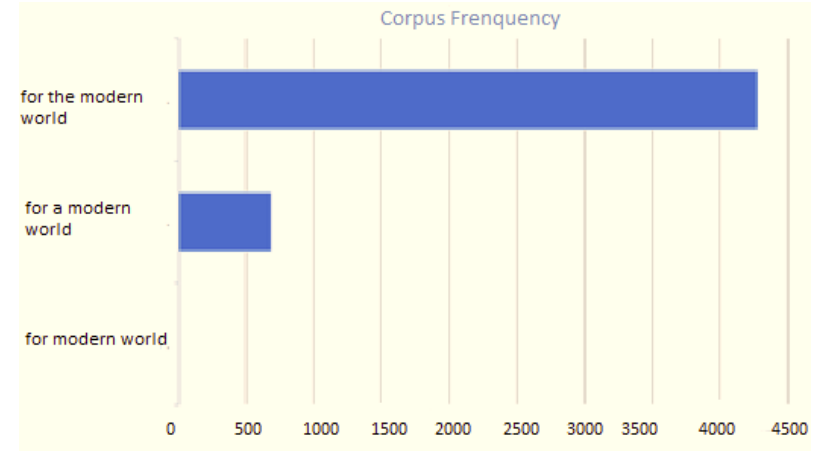

Fig. 4. Sample of Corpus Frequency

Pigai also offers a corpus dictionary (Fig. 5) where users can see the frequency of each phrase in Chinese students' English compositions and in authentic English. In this way, students can have a clear picture of how a certain phrase is used and thus improve their English fluency.

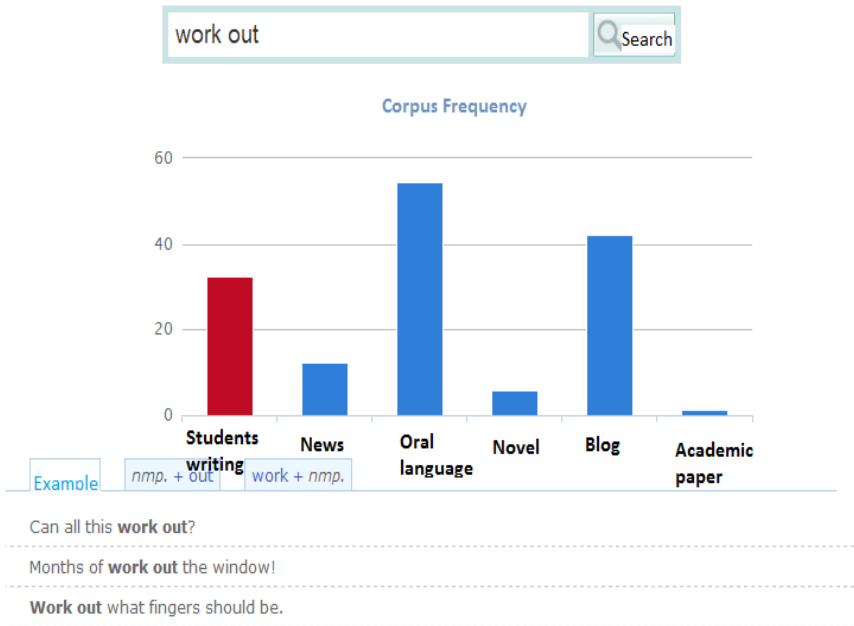

Fig. 5. Sample of Corpus Dictionary

As a student interviewed put it, "Pigai system suggests alternative advanced words for improvement. Every time I followed its suggestion, the grade would go 0.5 higher. It may sound too eager for quick success, but at least, I use 'play an essential role' instead of 'play an important part' in my writing now.” This feature increases students' vocabulary and improves their ability to distinguish synonyms. It also helps students to better use prepositional phrases and clauses which result in high grades and more sophisticated writing.

\section{CURRENT SHORTCOMINGS OF AES}

One of the strongest objections to computerized scoring is that computers are not capable of assessing an essay as human raters do because computers do "what [they are] programmed to do" and do not "appreciate" an essay (Page, 2003; Dikli, 2006)[6]. That is to say, there is no human appreciation and interaction when AES is employed in essay scoring. The system cannot recognize creativity, innovation, emotion or artistic concept in the essay submitted.

Educators opposing automated assessment software also argue that computers "cannot measure the essentials of effective written communication: accuracy, reasoning, adequacy of evidence, good sense, ethical position, convincing argument, meaningful organization and clarity, among others." (Markoff, 2013)[7]

In a questionnaire survey of 145 students on the use of Pigai in English writing course conducted by the author, over $85 \%$ students in the survey say they find the comments and correction from the computer useful or quite useful. 68.9\% say they feel better to see their essay rated and commented again by the teacher because they think the teacher can better understand them

One good example is that once the students were asked to write what they would do if given unlimited money for a day and whatever they buy with the money vanishes afterward. Most students wrote about buying food, luxuries, airline tickets, etc. However, one student wrote that he would buy all the trash and nuclear waste in the world and wait for them to disappear from the earth for good. This thought-provoking answer was unique, creative and full of goodwill, but wasn't adequately recognized by the system. In such cases, teachers should make an adjustment in the score and acknowledge the creativity.

Also, in the US, one longtime critic, Les Perelman, has drawn national attention several times for putting together nonsense essays that have fooled software grading programs into giving high marks. [7] In actual use of Pigai, it is also found that many high-scoring essays are using long and complicated sentences with clauses. A well-written essay with simple words and simple sentences usually don't get well-scored. When preparing for CET-4 and CET-6 exams, students would memorize some sentence patterns. They also find these sentence patterns are well accepted by Pigai and get high scores, while when graded by human graders, these compositions would be quite stale and sometimes even cliché.

When interviewed, some students also pointed out some of the not so intelligent aspects of Pigai, for example: abbreviation like AI gets lower score than its full version "Artificial Intelligence", and beautiful quotations from famous writers or poems are not appreciated by the computer.

Meanwhile, some students say they get the feedback saying "suspected Chinglish" and they don't understand why their expressions are incorrect or how to correct them. The following sentence is a "suspected Chinglish" from Pigai:

\section{He fell in love with his wife at first glance.}

Pigai suggests correction by adding an article "the" before "first". However, this article here is not necessary, as the expression "love at first sight" and the name of a 2017 TV movie "Love at First Glance" are well accepted by people.

As discussed before, Pigai compares the essay submitted with their corpus. When it finds that there is no such expression or usage in its own corpora, it gives the user a feedback. However, English is a constantly changing language and some linguistic phenomena or grammatical phenomena that are slowly accepted by people. On the other hand, there are some expressions accepted by native people but are not 
standard language. In this sense, people are superior to computers as they can learn and make better judgments.

\section{CONCLUSION}

Despite of its imperfection, AES can greatly promote the practice of college English writing and curriculum reform if used properly. It frees teachers for other constructive and advanced work. Meanwhile, its instant and intelligent feedback helps students improve their writing considerably. To minimize its drawbacks, the author suggests the following measures be taken in the application of AES:

- Increase the online peer-review process. Divide the students into groups and add peer review. The introduction of student mutual evaluation can make up for the lack of AES's appreciation of the essentials of effective writing. Speaking of peer review, although Pigai provides this feature, it cannot save group setting, where students can be assigned to certain groups according to their English level and help each other throughout the writing course. With each essay assigned, the teacher has to manually assign the reviewers or randomly assign reviewers, which is quite inconvenient and inefficient for group study.

- After peer review, the teacher should give a final score and comments. Teachers should appropriately adjust the scores according to each student's English level and learning attitude, so as to encourage and motivate them. This is especially important to promote students' writing enthusiasm.

- Based on the contents of the automatic correction, the teacher should summarize the common problems existing in the students' writing, explain the writing skills and expression methods, and help the students to accumulate and improve. This can be made in the form of Micro-Course Online Video, which is convenient for students to learn by themselves before class and make revision afterward. Also, the teacher can choose and display different model essays from the students each time to guide students to learn and build their confidence.
AES, represented by Pigai, is a very good teaching aid in English writing course. Giving full play to advantages of AES, such as time-saving, instant feedback and intelligent comments, the English writing class is shifting to a student-centered one. Students are now allowed to derive pleasure from English writing in the process of constant revision, self-exploration and self-innovative construction.

Teachers cannot rely entirely on AES. Teachers should act more like an organizer who combines the online feedback, peer feedback and teacher feedback together and helps improve student's writing ability and the quality of English writing course itself. Only by using AES reasonably and wisely, can teachers maximize the role of artificial intelligence, make up for the deficiencies of computer programs, and help students improve their writing skills.

\section{REFERENCES}

[1] Chen, J. Information Technology and Foreign Language Teaching Research: Theoretical Construction and Practical Exploration[C]. Shanghai: Shanghai Foreign Language Education Press. 2011. (in Chinese)

[2] Shermis, M. D. \& Burstein, J. Automated Essay Scoring: A cross-disciplinary perspective. Mahwah, NJ: Lawrence Erlbaum Associates. 2003.

[3] Dikli, S. An Overview of Automated Scoring of Essays. Journal of Technology, Learning, and Assessment, 5(1). Retrieved [date] from http://www.jtla.org. 2006.

[4] Salem, A. B. M. The potential role of artificial intelligence technology in Education (ERIC document reproduction service no ED 477 318) 2000

[5] Hou, F. The Application of Online Automated Essay Evaluation System in Teaching College English Writing-Based on Pigai[J]. The Chinese Journal of ICT in Education. 2015(16). (in Chinese)

[6] Page, E. B. Project Essay Grade: PEG. In M. D. Shermis \& J. Burstein (Eds.), Automated essay scoring: A cross-disciplinary perspective (pp. 43-54). Mahwah, NJ: Lawrence Erlbaum Associates. 2003.

[7] Markoff, J. Essay-Grading Software Offers Professors a Break[N]. New York Times. 2013-4-5. 